\title{
Assessment of genetic and non-genetic risk factors for venous thromboembolism in glioblastoma - The predictive significance of $B$ blood group
}

Menikae Kanchena Heenkenda, Annika Malmström, Malgorzata Lysiak, Munila Mudaisi, Charlotte Bratthall, Peter Milos, Michael Strandeus, Lisa Åkesson, Peter Söderkvist, Srinivas Uppugunduri and Abdimajid Osman

The self-archived postprint version of this journal article is available at Linköping University Institutional Repository (DiVA):

http://urn.kb.se/resolve?urn=urn:nbn:se:liu:diva-1625.37

N.B.: When citing this work, cite the original publication.

Heenkenda, M. K., Malmström, A., Lysiak, M., Mudaisi, M., Bratthall, C., Milos, P., Strandeus, M., Åkesson, L., Söderkvist, P., Uppugunduri, S., Osman, A., (2019), Assessment of genetic and nongenetic risk factors for venous thromboembolism in glioblastoma - The predictive significance of B blood group, Thrombosis Research, 183, 136-142. https://doi.org/10.1016/j.thromres.2019.10.009

Original publication available at:

https://doi.org/10.1016/j.thromres.2019.10.009

Copyright: Elsevier (12 months)

http://www.elsevier.com/

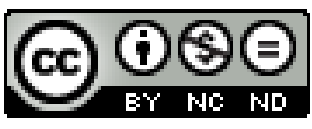




\section{Assessment of genetic and non-genetic risk factors for venous thromboembolism in glioblastoma - the predictive significance of B blood group}

Menikae K. Heenkenda ${ }^{1}$, Annika Malmström ${ }^{2}$, Malgorzata Lysiak ${ }^{3}$, Munila Mudaisi ${ }^{4}$, Charlotte Bratthäll ${ }^{5}$, Peter Milos ${ }^{6}$, Michael Strandeus ${ }^{7}$, Lisa Åkesson ${ }^{8}$, Peter Söderkvist ${ }^{3}$, Srinivas Uppugunduri ${ }^{8}$, Abdimajid Osman ${ }^{1} *$

${ }^{1}$ Department of Clinical Chemistry and Department of Clinical and Experimental Medicine, Linköping University, Linköping, Sweden.

${ }^{2}$ Department of Advanced Home Care and Department of Clinical and Experimental Medicine, Linköping University, Linköping, Sweden.

${ }^{3}$ Cell Biology, Department of Clinical and Experimental Medicine, Linköping University, Linköping, Sweden.

${ }^{4}$ Department of Oncology and Department of Clinical and Experimental Medicine, Linköping University, Linköping, Sweden.

${ }^{5}$ Department of Oncology, District Hospital, Kalmar, Sweden.

${ }^{6}$ Department of Neurosurgery and Department of Clinical and Experimental Medicine, Linköping University, Linköping, Sweden.

${ }^{7}$ Department of Oncology, Ryhov Hospital, Jönköping, Sweden.

${ }^{8}$ Regional Cancer Centre South East Sweden and Department of Clinical and Experimental Medicine, Linköping University, Linköping, Sweden.

*Corresponding author: Abdimajid Osman

Clinical Chemistry, ing. 64

University hospital

SE-581 83 Linköping, Sweden.

E-mail: majid.osman@liu.se 


\begin{abstract}
Introduction: Venous thromboembolism (VTE) is a common problem among patients with glioblastoma multiforme (GBM) and with some other cancers. Here, we evaluated genetic and non-genetic potential risk factors for VTE among GBM patients.

Materials and methods: A cohort of 139 patients treated with concomitant radiotherapy and temozolomide were included in the study. Next generation sequencing and genotyping approaches were applied to assess genetic risk factors in the haemostatic system. Clinical data including surgery, reoperation as well as blood group and patient information such as age and gender were available from patient records. Logistic regression analysis was performed to asses VTE risk.
\end{abstract}

Results: In the study 47 patients (34\%) were diagnosed for VTE during the course of their disease. When genetic and non-genetic potential risk factors were evaluated, only B blood group was found to be significantly associated with VTE incidence (odds ratio $[\mathrm{OR}]=6.91$; confidence interval $[\mathrm{CI}]=2.19-24.14 ; P=0.001)$. In contrast, $\mathrm{A}$ and $\mathrm{O}$ blood groups did not correlate with VTE risk. Frontal lobe tumor location also seemed to slightly increase VTE risk compared to other brain sites $(\mathrm{OR}=3.14 ; \mathrm{CI}=1.1-10.7)$ although the significance level was at borderline $(P=0.05)$. Current study identified B blood group as the component in non-O blood groups that is responsible for increased VTE risk.

Conclusion: In conclusion, these results suggest for the first time that B blood group is predictive for VTE incidence among patients with glioblastoma, information that may be potentially valuable when selecting GBM patients who are at risk for VTE for anticoagulant prophylaxis.

Keywords: ABO blood Groups; glioblastoma; Sequence Analysis, DNA; surgery; tumor location; Venous thromboembolism 


\section{Introduction}

Cancer progression is generally correlated with perturbations in the hemostatic system [1] and patients with different cancers have up to seven-fold increased risk of developing venous thromboembolism (VTE) [2, 3]. Patients with brain cancer, particularly those with high-grade glioma (grade 3-4) have a high risk of developing VTE [4, 5]. Glioblastoma multiforme $(\mathrm{GBM})$ is often associated with increased risk of developing coagulopathies and systemic thromboembolic disease [6], causing increased risk for morbidity and mortality. Patients with GBM have been found to harbor one of the highest risks for thrombosis-related complications among all medical and surgical patients [5]. The risk of incurring VTE was estimated up to $30 \%$ in some studies $[7,8]$. It is generally understood that cancer-associated thrombosis is a multifactorial disease involving tumor-related, patient-related and acquired factors. These include, but are not limited to, tissue factor expression [9], PAR thrombin receptors [10], cancer procoagulant proteins [11], and tumor cell-shed microparticles carrying procoagulants [12]. Type of surgery (gross total or subtotal tumor resection) as well as dose, type and duration of thromboprophylaxis, have been suggested to be important factors for the postoperative outcome of VTE [13]. In addition, general thrombosis risk factors such as high age, physical inactivity, and previous history of VTE are also known to increase VTE risk in cancer patients [14]. Factor V Leiden (c.1691G>A; rs6025) causing protein C resistance, and prothrombin G20210A (rs1799963) associated with elevated plasma prothrombin levels, are common risk factors for VTE in the general population [15-17] and would be expected to increase thrombosis risk in cancer patients as well. The implications of these SNPs for VTE development in cancer have been discussed in a number of studies [18-24]. There are conflicting results from those studies, with some reports suggesting an association between factor V Leiden (FVL) and VTE in different cancers [18-20, 24] whereas others could not verify a similar result [21-23]. Prothrombin G20210A has been more challenging to study in 
cancer patients due to its lower frequency. The ABO blood group is another common genetic factor with significance for thromboembolism. Current understanding is that non-O blood groups (A, B, AB), but not O blood type, increase thrombosis risk [25-28] and this is suggested to be explained by the fact that $\mathrm{ABO}(\mathrm{H})$ antigens are expressed on the N-linked glycan chains of circulating plasma von Willebrand factor (VWF) - a blood glycoprotein involved in hemostasis [29]. VWF is a major player in the primary hemostasis and platelet adhesion to the endothelium and elevated plasma VWF is associated with VTE [30]. Carriers of non-O blood group have been reported to show approximately $30 \%$ higher plasma VWF levels compared with O blood group carriers [31]. ABO blood group, FVL and prothrombin G20210A have been found to provide a predictive power for VTE in non-cancer patients [32]. In the present study, we have evaluated aforementioned risk factors for their associations with VTE in GBM patients. The overall aim of the present study was to assess whether VTE risk factors previously reported in the general population and in some cancers might play a role in GBM.

\section{Materials and methods}

\subsection{Study population}

The study cohort comprised 139 GBM patients recruited in Jönköping, Kalmar and Östergötland counties in south-eastern Sweden. All patients had after diagnostic surgery been found to be clinically fit for and were treated with concomitant radiotherapy (RT) and temozolomide (TMZ). The median RT duration was 41 days, with the vast majority of patients receiving standard 60 Gy (6 weeks) treatment. For those not progressing or deteriorating, adjuvant TMZ was also administered. Poor prognosis patients receiving single agent TMZ, radiotherapy alone or best supportive care only were not included so as to provide a homogeneous cohort. Detailed characteristics of the 139 GBM patients are given in 
Table 1. For next generation sequencing (NGS), DNA samples of 43 patients from this cohort were employed to explore single nucleotide variants with potential association to VTE. All patients received pre- and postoperativ thromboprophylaxis. In accordance with clinical routines at the university hospital in Linköping for treating glioblastoma patients, patients received 2500 IE tinzaparin one day before surgery and until they were deemed sufficiently mobilized by their attending physician which, depending on their postoperative functional status, could vary between a couple of days to several weeks with a mean duration time of two weeks. Consequently, neurologically and cognitive intact patients received shorter thromboprophylaxis than did those who were disabled. Case records were investigated retrospectively and information on thromboembolic incidents was collected during the entire course of GBM disease. Those patients experiencing at least one VTE episode were categorized as VTE cases.

\subsection{Blood groups and genotyping}

Information on $\mathrm{ABO}$ and $\mathrm{Rh}$ blood groups was collected from the medical records. Genomic DNA was extracted from whole blood, paraffin-embedded tumors or normal tissue samples using standard procedures. FVL and prothrombin G20210A SNPs were amplified with PCR and genotyped by pyrosequencing on a Pyromark Q24 instrument (Qiagen, Hilden, Germany). The rs56392308 SNP segregating A2 blood group was genotyped by pyrosequencing after PCR amplification. Detailed PCR and pyrosequencing protocols can be found in appendix A, supplementary materials and methods (file S1). Allele frequencies were compared with corresponding frequencies in the general population in Sweden reported within the SweGen project containing whole-genome variant frequencies for 1000 Swedish individuals (https://swefreq.nbis.se). 


\subsection{Next generation Sequencing (NGS)}

Targeted NGS using HaloPlex Target Enrichment reagents for library preparation was applied to sequence DNA of 43 patients. Coding sequences of 32 loci involved in thrombosis and hemostasis were sequenced (Table 2), using the manufacturer's instructions (Agilent Technologies, Santa Clara, CA, USA). DNA libraries were sequenced on a miSeq instrument with v2 reagent kit (Illumina Inc., San Diego, CA, USA), following the suppliers' recommendations. Sequence reads were aligned to the human reference genome (GRCh37/hg 19) employing Burrows-Wheeler Aligner (http://bio-bwa.sourceforge.net/). Variants were called by Samtools [33] using Ruby commands (https://www.ruby-lang.org/en/) and single nucleotide variants were annotated with Ensembl Variant Effect Predictor (https://www.ensembl.org/index.html).

\subsection{Statistical Analysis}

Statistics were performed with R software version 3.3.1 [34]. Logistic regression was used to calculate the risk contributed by each individual variable to predict the likelihood of developing VTE. Odds ratio (OR) and 95\% confidence intervals (CI) were calculated, and statistical significance was assumed at $p<0.05$. Fisher's exact test was used when data were unequally distributed among groups leaving less than 5 in any of the cells. Survival was computed by the Kaplan-Meier method. Deviation from Hardy-Weinberg equilibrium (HWE) was investigated by the chi-square test using a significance level at $P<0.05$.

\section{Results}

\subsection{Patients}

In a screened population of GBM patients, those with thrombosis before surgery were excluded from the study. The remaining cohort of 139 patients was followed until death or 
data cut-off as of May 8, 2019. Of these patients, 47 (34\%) were identified to have a verified thromboembolic event, mainly deep venous thrombosis (DVT; $\mathrm{n}=36$ ) or pulmonary embolism (PE; n=9). One patient had both DVT and PE, while another patient developed thrombophlebitis. All cases had symptomatic VTE and were diagnosed with ultrasonography (DVT) or computed tomography pulmonary angiography (PE). DNA was unavailable for 3 patients, which could not be included in analyses of FVL and prothrombin G20210A.

\subsection{Prothrombin G20210A, factor V Leiden and survival}

Only 4 patients displayed heterozygosity for prothrombin G20210A in the patient cohort genotyped ( $\mathrm{n}=136) ; 2$ with VTE and 2 without VTE. No homozygosity for the A allele was found. Fisher's exact test could not verify any statistically significant contribution to VTE in GBM by this variant. We also examined whether FVL had any impact on VTE outcome in GBM. Of the 136 GBM patients investigated, 19 (14\%) were heterozygous to FVL (factor V c.1691G>A). Homozygosity for FVL was not observed in the cohort examined. The calculated minor allele frequency at 0.07 for FVL and the observed genotype frequency in the GBM cohort was comparable with the FVL genotype data reported by Zöller et al. [35] for 4890 randomly selected subjects from the Swedish general population without history of VTE or cancer, and in accordance to Hardy-Weinberg distribution (Chi-value $=0.381)$. Thus, we found no evidence for association between FVL and VTE in GBM.

We could not document any statistically significant difference in survival between patients with or without VTE (Figure 1). Survival rate was close to $60 \%$ in both groups at one year.

\subsection{Age, surgery, reoperation and tumor localization}

A total number of 139 patients underwent diagnostic surgery, of which 63 (45\%) were radically operated, $54(39 \%)$ had partial surgery, and $22(16 \%)$ were biopsied. The majority of 
tumors were located in the frontal lobe, followed by the temporal lobe, parietal lobe, occipital lobe, and central lobe (Table 1). A majority of the patients (58\%) had no reoperation while the remaining patients $(42 \%)$ had one or more iterative surgery due to recurrent GBM (Table 1). To investigate whether age was important for VTE incidence, we compared age groups $<55$, 55-64 and >64 in the patient cohort. However, we found no statistically significant differences in VTE risk between the three groups. Age distribution was quite similar in VTE and nonVTE patients (Table 3). There was no evidence for an association between primary surgery or reoperation and VTE in GBM (Table 3). Neither did we find any evidence for a relationship between primary surgery and VTE after merging biopsy and partial surgery groups into one group and comparing it with the radical surgery group (Table 3). In contrast, tumor localization seemed to have some role for VTE risk (Table 3). Patients with frontal lobe tumor localization were observed to show increased risk for VTE (odds ratio $[\mathrm{OR}]=3.14$; confidence interval $[\mathrm{CI}]=1.1-10.7)$.

\subsection{Single nucleotide polymorphisms (SNPs) associated with ABO-blood group identified by} NGS analysis

We employed NGS technology and analyzed 32 genes involved in thrombosis and hemostasis, including the ABO locus, in a small cohort of 43 age- and treatment-matched GBM patients in two groups: a thrombosis group $(\mathrm{n}=18)$ and a non-thrombosis group $(\mathrm{n}=25)$ to infer gene variants associated with VTE. A cluster of SNPs in exon 8 of the ABO gene was found to correlate with blood group. Six SNPs; rs8176743, rs8176741, rs8176747, rs8176749, rs7853989 and rs8176740 marked differences between B and A alleles of ABO blood group, while SNP rs8176719 in exon 7 represented the only difference between O and non-O blood alleles. A majority of patients in the NGS cohort were A blood $(n=17)$ or O blood $(n=19)$ carriers. But when we assessed VTE risk in these patients, we found that neither A blood nor 
O blood group increased thrombosis risk. Conversely, we found that 4 out of 4 patients with B blood group had VTE in the NGS cohort. All of these patients also carried SNPs rs8176743, rs8176741, rs8176747, rs8176749, rs7853989 discriminating the B allele from the A allele of ABO blood group, which led us to ask whether B blood may play a role in VTE in GBM (see below).

\subsection{B blood group significantly increases VTE risk in GBM}

Based on the preliminary results from our NGS analysis (see above), we further investigated the type of ABO blood group that was potentially associated with increased risk for VTE in the GBM cohort $(n=139)$. The distribution of ABO blood groups among our GBM patients is shown in Table 3. As O blood group is generally believed to be protective for VTE risk [28], we compared non-O blood groups individually against $\mathrm{O}$ blood. Our analyses showed that B blood group, but not A blood type, significantly increased VTE risk (OR=6.9; CI=2.2-24.1; $P=0.001$ ) (Table 3). We also found that non-O blood groups represented an increased VTE risk in $\mathrm{GBM}(\mathrm{OR}=2.30 ; \mathrm{CI}=1.07-5.26 ; P=0.04)$ (Table 4), consistent with previous reports for the general population $[27,28]$ and for malignant glioma [36]. However, when subgroup analyses were performed, we found that A blood group had no contribution to this VTE risk (Table 4). There was no significant difference between $\mathrm{O}$ and A blood groups in VTE risk. The number of patients with $\mathrm{AB}$ blood was small (only 5) and when those patients were merged with B blood carriers, the risk for VTE was found to be significant in the combined B and $\mathrm{AB}$ groups as compared with $\mathrm{A}$ and $\mathrm{O}$ blood groups combined (Table 4). To examine whether subtype of A blood group had a role in VTE risk, we genotyped 64 patients with A blood group for A1 and A2 alleles using pyrosequencing. Of these, 46 patients displayed A1 genotype (16 with VTE and 30 without VTE) whereas 18 had A2 blood subtype (5 with VTE and 13 without VTE). No evidence was found that any of A1 or A2 blood group subtypes was 
associated with VTE, suggesting that A blood subtype had no role in VTE risk in our GBM cohort. Type of blood group did not have an impact on survival (Figure 2).

\section{Discussion}

In this study, we evaluated genetic and non-genetic factors as predictors for VTE in GBM. In our GBM cohort $(n=139), 34 \%$ of the patients developed VTE, consistent with the previously reported prevalence of up to $30 \%$ found in high-grade glioma patients [7, 8]. This high prevalence reveals the magnitude of the problem with VTE in GBM. While some of the risk factors involved in VTE are acquired, others are genetic and predating cancer incidence. Factor V Leiden and prothrombin G20210A are two of most well-studied gene variants associated with thrombophilia in Caucasian populations, and these two polymorphisms might be expected to increase VTE risk in GBM. Our study, however, could not document statistically significant contribution of any of these two variants to VTE in GBM. In the case of prothrombin G20210A, this study is consistent with previous studies that examined this variant in other cancers [37-41]. One study reported that prothrombin 20210A might be a possible cofactor in cancer pathogenesis [42]. However, one limitation with studies exploring the role of prothrombin G20210A in cancer, including ours, is the obviously insufficient statistical power due to the rarity of this mutation. In our case, only four patients were heterozygous for prothrombin G20210A in the patient cohort examined. In contrast, FVL is more prevalent, but most studies that found association between this variant and VTE were performed on non-GBM cancers [18-20]. One study investigated samples from unspecified brain tumors and reported FVL association with VTE [24], an observation that could not be corroborated in this study. It is plausible that FVL plays a more important role in other cancers and that its impact is less pronounced in GBM. 
Our study could not verify any significant impact of surgery on VTE, when radical surgery was compared with biopsy or partial resection either separately or combined (Table 3). The present study is consistent with that of Simanek et al. [13] who did not find a statistically significant association between biopsy and subtotal resection on one side and total resection on the other side although they observed a poorer survival as well as tendency toward an increased VTE risk with the former group. The small number of patients analyzed in their study ( $n=63$ ) was suggested to explain this lack of statistical significance for VTE [13]. Current study cohort comprised more than twice as many patients as in their study (139 versus 63 patients), but yet could not find any evidence for a surgery associated increase of VTE risk in GBM. However, the definition of radical versus subtotal or partial surgery varies somewhat in the literature. A partial resection, for instance, may indicate anything between $30 \%$ and 90\% tumor resection whereas Gross Total Resection (GTR) can be indicative of > $90 \%$ resection but may also mean a complete $(=100 \%)$ resection of contrast enhancement $[43,44]$. Nevertheless, our study could not corroborate that radical versus subtotal surgery plays a significant role for VTE in GBM. Surprisingly, there was a significant association between tumor localization and VTE, indicating an increased risk for VTE in frontally located GBM tumors $(\mathrm{OR}=3.14 ; \mathrm{CI}=1.07-10.65)$ although this had a borderline statistical significance $(\mathrm{P}=0.05)$ (Table 3). The frontal lobe is the largest brain lobe and also the most common site for glioblastoma [45]. GBM surgery in the frontal lobe can sometimes damage cortical motor areas and subcortical motor tracts causing permanent or transient postoperative motor deficits. Although we did not investigate postoperative complications in our cohort, it is tempting to speculate that such eventual postoperative motor deficits may increase the risk for VTE. Further studies are needed to investigate the association between tumor site and VTE risk in GBM. We found no statistically significant difference in survival between VTE and non-VTE 
patients, presumably mirroring the expected median survival of 14 months with the standard combinational TMZ and RT therapy given.

This study identified ABO blood group as a predictive factor for VTE in GBM, with B blood group significantly increasing the risk for VTE. The impact of ABO blood group on thrombosis is well known [46]. A recent Scandinavian study involving 1.5 million blood donors in Denmark and Sweden, with a follow-up time of 25 years, reported that non-O blood groups explained $>30 \%$ of all venous thromboembolic events [28]. What was particularly remarkable in the current study, however, was the relatively strong correlation between $\mathrm{B}$ blood group and VTE that we found in GBM (Table 4). Also, there was no association between A blood group and VTE in GBM, even when A1 and A2 subtypes were investigated either separately or combined. In contrast, when we merged $\mathrm{AB}$ and $\mathrm{B}$ blood carriers and compared that with combined $\mathrm{A}$ and $\mathrm{O}$ blood groups, we observed a significant difference in VTE risk between the two groups, with the former group markedly increasing VTE risk (Table 4). This strongly indicated that $\mathrm{B}$ antigen is presumably the component in the non-O blood groups that is responsible for the increased risk for VTE in GBM. To our knowledge this relationship has not been previously reported. It remains to be shown whether this correlation between B blood group and VTE observed in the current study also exists in other cancers or in the general population. Surprisingly though, an overwhelming majority of previous studies compared non-O blood groups with $\mathrm{O}$ blood, assuming $\mathrm{A}$ and $\mathrm{B}$ antigens to have similar effect on VTE, even though they are not chemically identical. Beyond VTE, there is a large body of literature describing an association between ABO blood groups and cancer [47]. Indeed, nearly 30 years ago, Annese et al. reported an association between B blood group and risk for pancreatic cancer [48]. It will therefore be important in the future to initiate larger studies that will further evaluate the role of B blood group in GBM. 
This study has some limitations. One obvious limitation is that only those patients who were found to be clinically fit for concomitant RT and TMZ treatment were included in the study. This was done in order to obtain a GBM cohort that was relatively homogeneous which clearly was an advantage when performing the logistic regression analysis. Thus, this study is not representative for patients with poor prognosis or those receiving single agent TMZ, radiotherapy alone or best supportive care only. Another limitation is the retrospective nature of the study. As a result, this study did not evaluate several other known VTE risk factors including, but not limited to, elevated platelet $\left(>350 \times 10^{9} / \mathrm{L}\right)$ or leukocyte $\left(>11 \times 10^{9} / \mathrm{L}\right)$ counts, D-dimer, tissue factor expression by tumor cells, circulating tissue factor, soluble Pselectin, C-reactive protein as well as platelet function. Most of these biochemical analyses are not performed on a standard basis for all GBM patients and were thus not available in patient records. Hence, it was not possible to include all these factors in the logistic regression analysis, which was obviously a limitation. Regardless of VTE risk factors, however, our finding showing that $34 \%$ of the GBM cohort had VTE is consistent with the previously estimated proportion of nearly $30 \%$ VTE cases in high-grade glioma patients $[7,8]$.

\section{Conclusions}

In conclusion, the present study has evaluated a number of genetic and non-genetic potential VTE risk factors in GBM patients. We found that frontal lobe tumor site might be associated with VTE and we propose B blood group as the individually most significant risk factor for VTE in GBM. Patients with B blood group could benefit from anticoagulant therapy when selecting VTE risk patients.

\section{Acknowledgements}


We are indebted to Dr. Jon Jonasson at the department of Clinical Genetics, University Hospital in Linköping, who is greatly acknowledged for his help with the bioinformatics and for the ABO blood group allele data analysis.

\section{Funding}

This study was supported by grants from the Medical Research Council of Southeast Sweden (FORSS) and County Council of Region Östergötland, Sweden.

\section{Declaration of interest}

The authors declare that they have no competing interests

\section{Appendix A. Supplementary data}

Supplementary materials and methods can be found in file S1

\section{References}

[1] D. Garnier, N. Magnus, E. D'Asti, M. Hashemi, B. Meehan, C. Milsom, J. Rak, Genetic pathways linking hemostasis and cancer, Thromb Res 129 Suppl 1 (2012) S22-9.

[2] Y. Hisada, J.E. Geddings, C. Ay, N. Mackman, Venous thrombosis and cancer: from mouse models to clinical trials, J Thromb Haemost 13(8) (2015) 1372-82.

[3] T. Wun, R.H. White, Epidemiology of cancer-related venous thromboembolism, Best Pract Res Clin Haematol 22(1) (2009) 9-23.

[4] M. Jeraq, D.J. Cote, T.R. Smith, Venous Thromboembolism in Brain Tumor Patients, Adv Exp Med Biol 906 (2017) 215-228.

[5] J.R. Perry, Thromboembolic disease in patients with high-grade glioma, Neuro Oncol 14 Suppl 4 (2012) iv73-80.

[6] N. Magnus, E. D'Asti, D. Garnier, B. Meehan, J. Rak, Brain neoplasms and coagulation, Semin Thromb Hemost 39(8) (2013) 881-95.

[7] A.A. Brandes, E. Scelzi, G. Salmistraro, M. Ermani, C. Carollo, F. Berti, P. Zampieri, C. Baiocchi, M.V. Fiorentino, Incidence of risk of thromboembolism during treatment high-grade gliomas: a prospective study, Eur J Cancer 33(10) (1997) 1592-6.

[8] S. Yust-Katz, J.J. Mandel, J. Wu, Y. Yuan, C. Webre, T.A. Pawar, H.S. Lhadha, M.R. Gilbert, T.S. Armstrong, Venous thromboembolism (VTE) and glioblastoma, J Neurooncol 124(1) (2015) 87-94. 
[9] J. Contrino, G. Hair, D.L. Kreutzer, F.R. Rickles, In situ detection of tissue factor in vascular endothelial cells: correlation with the malignant phenotype of human breast disease, Nat Med 2(2) (1996) 209-15.

[10] S. Even-Ram, B. Uziely, P. Cohen, S. Grisaru-Granovsky, M. Maoz, Y. Ginzburg, R. Reich, I. Vlodavsky, R. Bar-Shavit, Thrombin receptor overexpression in malignant and physiological invasion processes, Nat Med 4(8) (1998) 909-14.

[11] N.L. Kee, J. Krause, G.L. Blatch, K. Muramoto, K. Sakka, M. Sakka, R.J. Naude, L. Wagner, R. Wolf, J.U. Rahfeld, H.U. Demuth, W.P. Mielicki, C.L. Frost, The proteolytic profile of human cancer procoagulant suggests that it promotes cancer metastasis at the level of activation rather than degradation, Protein J 34(5) (2015) 338-48.

[12] A. Falanga, L. Russo, V. Milesi, A. Vignoli, Mechanisms and risk factors of thrombosis in cancer, Crit Rev Oncol Hematol 118 (2017) 79-83.

[13] R. Simanek, R. Vormittag, M. Hassler, K. Roessler, M. Schwarz, C. Zielinski, I. Pabinger, C. Marosi, Venous thromboembolism and survival in patients with high-grade glioma, Neuro Oncol 9(2) (2007) 89-95.

[14] J.F. Timp, S.K. Braekkan, H.H. Versteeg, S.C. Cannegieter, Epidemiology of cancer-associated venous thrombosis, Blood 122(10) (2013) 1712-23.

[15] R.M. Bertina, B.P. Koeleman, T. Koster, F.R. Rosendaal, R.J. Dirven, H. de Ronde, P.A. van der Velden, P.H. Reitsma, Mutation in blood coagulation factor $V$ associated with resistance to activated protein C, Nature 369(6475) (1994) 64-7.

[16] S.R. Poort, F.R. Rosendaal, P.H. Reitsma, R.M. Bertina, A common genetic variation in the 3'untranslated region of the prothrombin gene is associated with elevated plasma prothrombin levels and an increase in venous thrombosis, Blood 88(10) (1996) 3698-703.

[17] F.R. Rosendaal, Causes of venous thrombosis, Thrombosis journal 14(Suppl 1) (2016) 24.

[18] J.W. Blom, C.J. Doggen, S. Osanto, F.R. Rosendaal, Malignancies, prothrombotic mutations, and the risk of venous thrombosis, JAMA 293(6) (2005) 715-22.

[19] A. Eroglu, Y. Egin, R. Cam, N. Akar, The 19-bp deletion of dihydrofolate reductase (DHFR), methylenetetrahydrofolate reductase (MTHFR) C677T, Factor V Leiden, prothrombin G20210A polymorphisms in cancer patients with and without thrombosis, Ann Hematol 88(1) (2009) 73-6.

[20] J.E. Garber, S. Halabi, S.M. Tolaney, E. Kaplan, L. Archer, J.N. Atkins, S. Edge, C.L. Shapiro, L. Dressler, E.D. Paskett, G. Kimmick, J. Orcutt, A. Scalzo, E. Winer, E. Levine, N. Shahab, N. Berliner, Cancer, B. Leukemia Group, Factor $V$ Leiden mutation and thromboembolism risk in women receiving adjuvant tamoxifen for breast cancer, J Natl Cancer Inst 102(13) (2010) 942-9.

[21] M. Kennedy, A.C. Andreescu, M.S. Greenblatt, H. Jiang, C.A. Thomas, L. Chassereau, C. Wong, P. Durda, M. Cushman, Factor V Leiden, prothrombin 20210A and the risk of venous thrombosis among cancer patients, Br J Haematol 128(3) (2005) 386-8.

[22] S. Arslan, S. Manduz, K. Epozturk, O. Karahan, I. Akkurt, Association of deep venous thrombosis with prothrombotic gene polymorphism identified in lung cancer cases, Mol Biol Rep 38(4) (2011) 2395-400.

[23] M. Mandala, S. Barni, M. Prins, R. Labianca, C. Tondini, L. Russo, A. Milesi, M. Cremonesi, M. Zaccanelli, C. Regonesi, C. Moro, A. Falanga, Acquired and inherited risk factors for developing venous thromboembolism in cancer patients receiving adjuvant chemotherapy: a prospective trial, Ann Oncol 21(4) (2010) 871-6.

[24] I. Pabinger, C. Ay, D. Dunkler, J. Thaler, E.M. Reitter, C. Marosi, C. Zielinski, C. Mannhalter, Factor $\checkmark$ Leiden mutation increases the risk for venous thromboembolism in cancer patients - results from the Vienna Cancer And Thrombosis Study (CATS), J Thromb Haemost 13(1) (2015) 17-22.

[25] M. Franchini, M. Makris, Non-O blood group: an important genetic risk factor for venous thromboembolism, Blood Transfus 11(2) (2013) 164-5.

[26] V.M. Morelli, M.C. De Visser, H.L. Vos, R.M. Bertina, F.R. Rosendaal, ABO blood group genotypes and the risk of venous thrombosis: effect of factor V Leiden, J Thromb Haemost 3(1) (2005) 183-5.

[27] D.A. Tregouet, S. Heath, N. Saut, C. Biron-Andreani, J.F. Schved, G. Pernod, P. Galan, L. Drouet, D. Zelenika, I. Juhan-Vague, M.C. Alessi, L. Tiret, M. Lathrop, J. Emmerich, P.E. Morange, Common 
susceptibility alleles are unlikely to contribute as strongly as the FV and ABO loci to VTE risk: results from a GWAS approach, Blood 113(21) (2009) 5298-303.

[28] S.K. Vasan, K. Rostgaard, A. Majeed, H. Ullum, K.E. Titlestad, O.B. Pedersen, C. Erikstrup, K.R. Nielsen, M. Melbye, O. Nyren, H. Hjalgrim, G. Edgren, ABO Blood Group and Risk of Thromboembolic and Arterial Disease: A Study of 1.5 Million Blood Donors, Circulation 133(15) (2016) 1449-57; discussion 1457.

[29] X. Liu, X. Chen, J. Yang, R. Guo, Association of ABO blood groups with von Willebrand factor, factor VIII and ADAMTS-13 in patients with lung cancer, Oncol Lett 14(3) (2017) 3787-3794.

[30] P. Calabro, F. Gragnano, E. Golia, E.L. Grove, von Willebrand Factor and Venous Thromboembolism: Pathogenic Link and Therapeutic Implications, Semin Thromb Hemost 44(3) (2018) 249-260.

[31] K.H. Orstavik, P. Magnus, H. Reisner, K. Berg, J.B. Graham, W. Nance, Factor VIII and factor IX in a twin population. Evidence for a major effect of ABO locus on factor VIII level, American journal of human genetics 37(1) (1985) 89-101.

[32] A. van Hylckama Vlieg, L.E. Flinterman, L.A. Bare, S.C. Cannegieter, P.H. Reitsma, A.R. Arellano, C.H. Tong, J.J. Devlin, F.R. Rosendaal, Genetic variations associated with recurrent venous thrombosis, Circulation. Cardiovascular genetics 7(6) (2014) 806-13.

[33] H. Li, B. Handsaker, A. Wysoker, T. Fennell, J. Ruan, N. Homer, G. Marth, G. Abecasis, R. Durbin, S. Genome Project Data Processing, The Sequence Alignment/Map format and SAMtools, Bioinformatics 25(16) (2009) 2078-9.

[34] R Core Team. A Language and Environment for Statistical Computing. R Foundation for Statistical Computing. 2016, Vienna, Austria. https://www.R-project.org/.).

[35] B. Zoller, O. Melander, P.J. Svensson, G. Engstrom, Factor V Leiden paradox in a middle-aged Swedish population: A prospective study, Vasc Med 23(1) (2018) 52-59.

[36] M.B. Streiff, J. Segal, S.A. Grossman, T.S. Kickler, E.G. Weir, ABO blood group is a potent risk factor for venous thromboembolism in patients with malignant gliomas, Cancer 100(8) (2004) 171723.

[37] E. Ramacciotti, N. Wolosker, P. Puech-Leao, E.A. Zeratti, P.R. Gusson, A. del Giglio, R.F. Franco, Prevalence of factor V Leiden, FII G20210A, FXIII Val34Leu and MTHFR C677T polymorphisms in cancer patients with and without venous thrombosis, Thromb Res 109(4) (2003) 171-4.

[38] E. Vairaktaris, C. Yapijakis, J. Wiltfang, J. Ries, A. Vylliotis, S. Derka, S. Vasiliou, F.W. Neukam, Are factor $\mathrm{V}$ and prothrombin mutations associated with increased risk of oral cancer?, Anticancer Res 25(3c) (2005) 2561-5.

[39] S. Ghasemi, A. Tavakoli, M. Moghadam, M.A. Zargar, M. Abbaspour, N. Hatamnejadian, A. Ebrahimi, Risk of prostate cancer and thrombosis-related factor polymorphisms, Biomed Rep 2(1) (2014) 53-56.

[40] M. Mandala, G. Curigliano, P. Bucciarelli, G. Ferretti, P.M. Mannucci, M. Colleoni, A. Ventura, G. Peruzzotti, G. Severi, P.G. Pelicci, R. Biffi, F. Orsi, S. Cinieri, A. Goldhirsch, Factor V Leiden and G20210A prothrombin mutation and the risk of subclavian vein thrombosis in patients with breast cancer and a central venous catheter, Ann Oncol 15(4) (2004) 590-3.

[41] A. Eroglu, A. Ulu, R. Cam, C. Kurtman, N. Akar, Prevalence of Factor V 1691 G-A (Leiden) and prothrombin G20210A polymorphisms and the risk of venous thrombosis among cancer patients, J Thromb Thrombolysis 23(1) (2007) 31-4.

[42] R. Pihusch, G. Danzl, M. Scholz, D. Harich, M. Pihusch, P. Lohse, E. Hiller, Impact of thrombophilic gene mutations on thrombosis risk in patients with gastrointestinal carcinoma, Cancer 94(12) (2002) 3120-6.

[43] F. Pessina, P. Navarria, L. Cozzi, R. Ruda, M.C. Nibali, M. Simonelli, F. Costa, A. Santoro, E. Clerici, G. Carta, M. Scorsetti, L. Bello, Is surgical resection useful in elderly newly diagnosed glioblastoma patients? Outcome evaluation and prognostic factors assessment, Acta Neurochir (Wien) 160(9) (2018) 1779-1787. 
[44] F. Incekara, S. Koene, A. Vincent, M.J. van den Bent, M. Smits, Association Between Supratotal Glioblastoma Resection and Patient Survival: A Systematic Review and Meta-Analysis, World Neurosurg (2019).

[45] E.V. Walker, F.G. Davis, C.f. affiliates, Malignant primary brain and other central nervous system tumors diagnosed in Canada from 2009 to 2013, Neuro Oncol (2019).

[46] F. Dentali, A.P. Sironi, W. Ageno, S. Turato, C. Bonfanti, F. Frattini, S. Crestani, M. Franchini, NonO blood type is the commonest genetic risk factor for VTE: results from a meta-analysis of the literature, Semin Thromb Hemost 38(5) (2012) 535-48.

[47] G.M. Liumbruno, M. Franchini, Beyond immunohaematology: the role of the ABO blood group in human diseases, Blood Transfus 11(4) (2013) 491-9.

[48] V. Annese, M. Minervini, A. Gabbrielli, G. Gambassi, R. Manna, ABO blood groups and cancer of the pancreas, Int J Pancreatol 6(2) (1990) 81-8. 
Table 1. Basic characteristics for 139 GBM patients included in this study.

\begin{tabular}{|c|c|c|}
\hline Gender & $\begin{array}{l}\text { Male } \\
\text { Female }\end{array}$ & $\begin{array}{l}87(63 \%) \\
52(37 \%)\end{array}$ \\
\hline Age & $\begin{array}{l}<55 \\
55-64 \\
>=65\end{array}$ & $\begin{array}{l}50(36 \%) \\
50(28 \%) \\
39(36 \%)\end{array}$ \\
\hline Surgery & $\begin{array}{l}\text { Radical } \\
\text { Partial } \\
\text { Biopsy }\end{array}$ & $\begin{array}{l}63(45 \%) \\
54(39 \%) \\
22(16 \%)\end{array}$ \\
\hline Location & $\begin{array}{l}\text { Frontal lobe } \\
\text { Temporal lobe } \\
\text { Parietal lobe } \\
\text { Occipital lobe } \\
\text { Central }\end{array}$ & $\begin{array}{l}50(36 \%) \\
41(29 \%) \\
25(18 \%) 17(12 \%) \\
6(4 \%)\end{array}$ \\
\hline Reoperation & $\begin{array}{l}\text { No } \\
\text { One time } \\
\text { More than one }\end{array}$ & $\begin{array}{l}80(58 \%) \\
44(32 \%) \\
15(11 \%)\end{array}$ \\
\hline VTE diagnosis & $\begin{array}{l}\text { With VTE } \\
\text { Without VTE } \\
\text { WI }\end{array}$ & $\begin{array}{l}47(34 \%) \\
92(66 \%)\end{array}$ \\
\hline $\mathrm{ABO}$ and Rhesus blood groups & 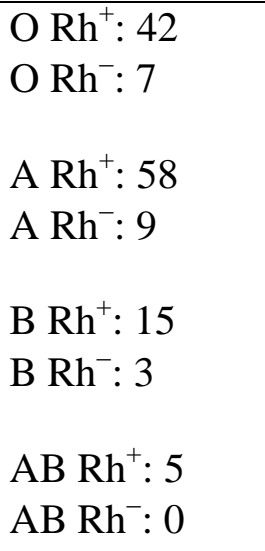 & $\begin{array}{l}49(35 \%) \\
67(48 \%) \\
18(13 \%) \\
5(4 \%)\end{array}$ \\
\hline Factor V Leiden & $\begin{array}{l}\text { Yes } \\
\text { No } \\
\text { No sample }\end{array}$ & $\begin{array}{l}19(14 \%) \\
117(84 \%) \\
3(2 \%)\end{array}$ \\
\hline Prothrombin & $\begin{array}{l}\text { Yes } \\
\text { No } \\
\text { No sample }\end{array}$ & $\begin{array}{l}4(3 \%) \\
132(95 \%) \\
3(2 \%)\end{array}$ \\
\hline
\end{tabular}

"Venous thromboembolism 
Table 2. List of 32 genes sequenced in the study by next generation sequencing

\begin{tabular}{|c|c|c|c|}
\hline Symbol & Approved name & HGNC ID & Location \\
\hline $\mathrm{ABO}$ & $\begin{array}{l}\text { ABO, alpha 1-3-N- } \\
\text { acetylgalactosaminyltransferase and } \\
\text { alpha 1-3-galactosyltransferase }\end{array}$ & HGNC:79 & $9 q 34.2$ \\
\hline CPB2 & carboxypeptidase B2 & HGNC:2300 & $13 q 14.13$ \\
\hline CYP4V2 & $\begin{array}{l}\text { cytochrome P450 family } 4 \\
\text { subfamily V member } 2\end{array}$ & HGNC:23198 & $\begin{array}{l}4 \mathrm{q} 35.1- \\
\mathrm{q} 35.2\end{array}$ \\
\hline F10 & coagulation factor $\mathrm{X}$ & HGNC:3528 & $13 q 34$ \\
\hline F11 & coagulation factor XI & HGNC:3529 & $4 q 35.2$ \\
\hline F13A1 & coagulation factor XIII A chain & HGNC:3531 & $6 \mathrm{p} 25.1$ \\
\hline F13B & coagulation factor XIII B chain & HGNC:3534 & $1 \mathrm{q} 31.3$ \\
\hline $\mathrm{F} 2$ & coagulation factor II, thrombin & HGNC:3535 & $11 \mathrm{p} 11.2$ \\
\hline FY2R & $\begin{array}{l}\text { coagulation factor II thrombin } \\
\text { receptor }\end{array}$ & HGNC:3537 & $5 q 13.3$ \\
\hline F2RL3 & $\begin{array}{l}\text { F2R like thrombin or trypsin } \\
\text { receptor } 3\end{array}$ & HGNC:3540 & $19 \mathrm{p} 13.11$ \\
\hline $\mathrm{F} 3$ & coagulation factor III, tissue factor & HGNC:3541 & $1 \mathrm{p} 21.3$ \\
\hline F5 & coagulation factor $\mathrm{V}$ & HGNC:3542 & $1 \mathrm{q} 24.2$ \\
\hline F7 & coagulation factor VII & HGNC:3544 & $13 q 34$ \\
\hline F8 & coagulation factor VIII & HGNC:3546 & $\mathrm{Xq} 28$ \\
\hline F9 & coagulation factor IX & HGNC:3551 & $\mathrm{Xq} 27.1$ \\
\hline FGA & fibrinogen alpha chain & HGNC:3661 & $4 \mathrm{q} 31.3$ \\
\hline FGB & fibrinogen beta chain & HGNC:3662 & $4 q 31.3$ \\
\hline FGG & fibrinogen gamma chain & HGNC:3694 & $4 q 32.1$ \\
\hline GP6 & glycoprotein VI platelet & HGNC:14388 & $19 q 13.42$ \\
\hline PLAT & plasminogen activator, tissue type & HGNC:9051 & $8 \mathrm{p} 11.21$ \\
\hline PLAU & plasminogen activator, urokinase & HGNC:9052 & $10 \mathrm{q} 22.2$ \\
\hline PLG & plasminogen & HGNC:9071 & $6 q 26$ \\
\hline PROC & $\begin{array}{l}\text { protein } \mathrm{C} \text {, inactivator of coagulation } \\
\text { factors } \mathrm{Va} \text { and VIIIa }\end{array}$ & HGNC:9451 & $2 \mathrm{q} 14.3$ \\
\hline PROS1 & protein $S$ & HGNC:9456 & $3 q 11.1$ \\
\hline SERPINC1 & serpin family $\mathrm{C}$ member 1 & HGNC:775 & $1 \mathrm{q} 25.1$ \\
\hline SERPIND1 & serpin family D member 1 & HGNC:4838 & $22 q 11.21$ \\
\hline SERPINE1 & serpin family E member 1 & HGNC:8583 & $7 q 22.1$ \\
\hline SERPINF2 & serpin family F member 2 & HGNC:9075 & $17 \mathrm{p} 13.3$ \\
\hline TFPI & tissue factor pathway inhibitor & HGNC:11760 & $2 q 32.1$ \\
\hline THBD & thrombomodulin & HGNC:11784 & $20 \mathrm{p} 11.21$ \\
\hline THPO & thrombopoietin & HGNC:11795 & $3 q 27.1$ \\
\hline VWF & von Willebrand factor & HGNC:12726 & $12 \mathrm{p} 13.31$ \\
\hline
\end{tabular}


Table 3. Assessment of predictive variables against risk for venous thromboembolism (VTE) in GBM patients $(\mathbf{n = 1 3 9})$. Statistically significant associations are highlighted with bold text.

\begin{tabular}{|c|c|c|c|c|}
\hline--- & $\begin{array}{l}\text { With VTE } \\
(n=47)\end{array}$ & $\begin{array}{l}\text { Without VTE } \\
(\mathrm{n}=92)\end{array}$ & Odds ratio $\left(\mathrm{CI}^{\mathrm{Il}}\right)$ & P-Value \\
\hline Age at surgery & $\begin{array}{l}\text { Median:58 (39- } \\
69)\end{array}$ & $\begin{array}{l}\text { Median:60 } \\
(25-76)\end{array}$ & $0.99(0.95-1.03)$ & 0.54 \\
\hline $\begin{array}{l}\text { Gender } \\
\text { Female (ref) } \\
\text { Male }\end{array}$ & $\begin{array}{l}18(38 \%) \\
29(62 \%)\end{array}$ & $\begin{array}{l}34(37 \%) \\
58(63 \%)\end{array}$ & 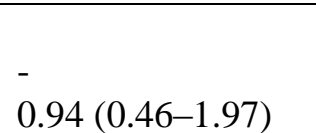 & $\begin{array}{c}- \\
0.88\end{array}$ \\
\hline $\begin{array}{l}\text { Primary Surgery } \\
\text { Radical (ref) } \\
\text { Partial } \\
\text { Biopsy } \\
\text { Partial/Biopsy }\end{array}$ & $\begin{array}{l}20(43 \%) \\
19(41 \%) \\
7(15 \%) \\
26(57 \%)\end{array}$ & $\begin{array}{l}42(46 \%) \\
35(38 \%) \\
15(16 \%) \\
50(54 \%)\end{array}$ & $\begin{array}{l}- \\
1.14(0.53-2.47) \\
0.98(0.33-2.72) \\
1.09(0.54-2.24)\end{array}$ & $\begin{array}{l}- \\
0.74 \\
0.97 \\
0.81\end{array}$ \\
\hline $\begin{array}{l}\text { Location } \\
\text { Parietal lobe (ref) } \\
\text { Frontal lobe } \\
\text { Occipital lobe } \\
\text { Temporal lobe } \\
\text { Central }\end{array}$ & $\begin{array}{l}5(11 \%) \\
22(47 \%) \\
6(13 \%) \\
12(26 \%) \\
2(4 \%) \\
\end{array}$ & $\begin{array}{l}20(22 \%) \\
28(30 \%) \\
11(12 \%) \\
29(32 \%) \\
4(4 \%)\end{array}$ & $\begin{array}{l}- \\
\mathbf{3 . 1 4}(\mathbf{1 . 0 7}-\mathbf{1 0 . 6 5}) \\
2.18(0.54-9.23) \\
1.66(0.52-5.87) \\
2.00(0.23-13.85)\end{array}$ & $\begin{array}{l}- \\
\mathbf{0 . 0 5} \\
0.27 \\
0.41 \\
0.49 \\
\end{array}$ \\
\hline $\begin{array}{l}\text { Reoperation } \\
\text { No (ref) } \\
\text { One time } \\
\text { More than one }\end{array}$ & $\begin{array}{l}29(62 \%) \\
13(28 \%) \\
5(11 \%)\end{array}$ & $\begin{array}{l}51(55 \%) \\
31(34 \%) \\
10(11 \%)\end{array}$ & $\begin{array}{l}- \\
0.74(0.33-1.61) \\
0.88(0.25-2.73)\end{array}$ & $\begin{array}{c}- \\
0.45 \\
0.83\end{array}$ \\
\hline $\begin{array}{l}\text { Blood group } \\
\text { O (ref) } \\
\text { A } \\
\text { AB } \\
\text { B }\end{array}$ & $\begin{array}{l}11(23 \%) \\
22(47 \%) \\
2(4 \%) \\
12(26 \%)\end{array}$ & $\begin{array}{l}38(41 \%) \\
45(49 \%) \\
3(3 \%) \\
6(7 \%)\end{array}$ & $\begin{array}{l}- \\
1.69(0.74-4.03) \\
2.30(0.28-15.67) \\
\mathbf{6 . 9 1}(\mathbf{2 . 1 9}-\mathbf{2 4 . 1 4})\end{array}$ & $\begin{array}{c}- \\
0.22 \\
0.39 \\
\mathbf{0 . 0 0 1}\end{array}$ \\
\hline
\end{tabular}

${ }^{\text {"Confidence interval }}$ 
Table 4. Association of blood groups with VTE in GBM. Statistically significant associations are highlighted with bold text.

\begin{tabular}{|c|c|c|c|c|}
\hline Blood group & $\begin{array}{c}\text { With VTE } \\
(n=47)\end{array}$ & $\begin{array}{c}\text { Without VTE } \\
(n=92)\end{array}$ & $\begin{array}{l}\text { Odds ratio } \\
(95 \% \mathrm{CI})\end{array}$ & P-Value \\
\hline $\begin{array}{l}\text { O blood group (ref) } \\
\text { Non-O blood group }\end{array}$ & $\begin{array}{l}11 \\
36\end{array}$ & $\begin{array}{l}38 \\
54\end{array}$ & $2.30(1.07-5.26)$ & 0.04 \\
\hline $\begin{array}{l}\text { O blood group (ref) } \\
\text { A blood group }\end{array}$ & $\begin{array}{l}11 \\
22\end{array}$ & $\begin{array}{l}38 \\
45\end{array}$ & $1.69(0.74-4.03)$ & 0.22 \\
\hline $\begin{array}{l}\text { O blood group (ref) } \\
\text { B blood group }\end{array}$ & $\begin{array}{l}11 \\
12\end{array}$ & $\begin{array}{c}38 \\
6\end{array}$ & $6.91(2.19-24.14)$ & 0.001 \\
\hline $\begin{array}{l}\text { O blood group (ref) } \\
\text { AB blood group }\end{array}$ & $\begin{array}{c}11 \\
2\end{array}$ & $\begin{array}{c}38 \\
3\end{array}$ & $2.30(0.28-15.67)$ & 0.39 \\
\hline $\begin{array}{l}\text { A blood group (ref) } \\
\text { B blood group }\end{array}$ & $\begin{array}{l}22 \\
12\end{array}$ & $\begin{array}{c}45 \\
6\end{array}$ & $4.09(1.40-13.13)$ & 0.01 \\
\hline $\begin{array}{l}\text { A blood group (ref) } \\
\text { AB blood group }\end{array}$ & $\begin{array}{c}22 \\
2\end{array}$ & $\begin{array}{c}45 \\
6\end{array}$ & $1.36(0.17-8.81)$ & 0.74 \\
\hline $\begin{array}{l}\text { A, O blood group (ref) } \\
\text { B blood group }\end{array}$ & $\begin{array}{l}33 \\
12\end{array}$ & $\begin{array}{c}83 \\
6\end{array}$ & $5.03(1.80-15.50)$ & 0.003 \\
\hline $\begin{array}{l}\text { A, O blood group (ref) } \\
\text { B, AB blood group }\end{array}$ & $\begin{array}{l}33 \\
14\end{array}$ & $\begin{array}{c}83 \\
9\end{array}$ & $3.91(1.57-10.24)$ & 0.004 \\
\hline
\end{tabular}




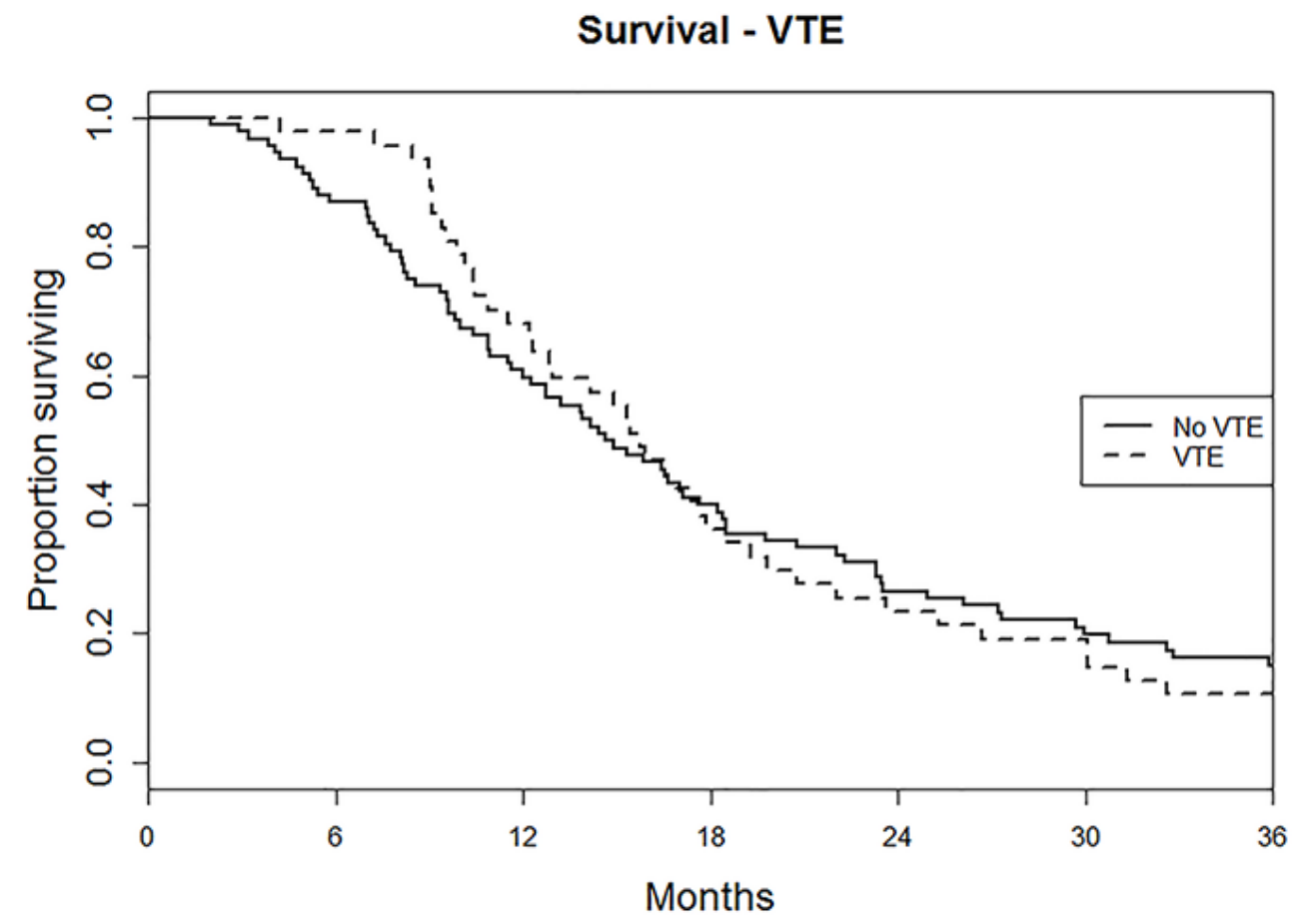

Fig. 1. Kaplan-Meier diagram illustrating VTE and survival relationship for 139 GBM patients. No statistically significant difference in survival was found between the two groups. 


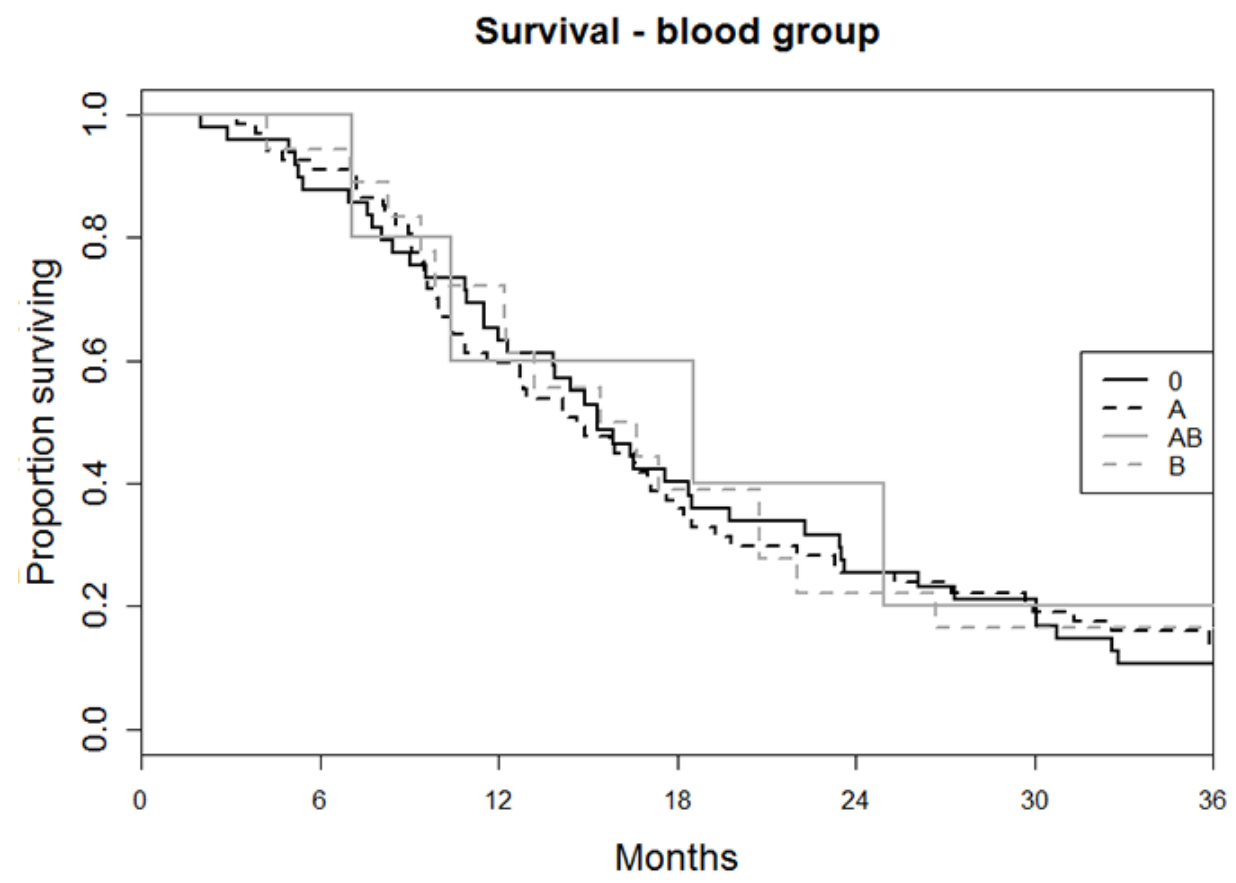

Fig. 2. Kaplan-Meir survival chart depicting ABO blood groups $(\mathrm{O}, \mathrm{A}, \mathrm{B}, \mathrm{AB})$. There was no statistically significant difference in survival between the different blood groups. 